\title{
Anplastology: Moving Forward
}

\section{Ziyad Alharbi ${ }^{1,2}$}

${ }^{1}$ Department of Plastic, Reconstructive and Hand Surgery - Burn Center, Medical Faculty, RWTH Aachen University, Aachen, Germany ${ }^{2}$ Division of Plastic Surgery, Specialized Surgery Center, King Abdullah Medical City, Kingdom of Saudi Arabia

Anaplastology has become a dynamic field with an interdisciplinary approach toward improving the quality of life for people with bodily or facial defects through a reconstruction process that employs prosthetic rehabilitation. The field has extended its role by interacting with other areas of reconstruction especially those involving the head and neck. Reconstructive surgeons aim to restore malformed or absent parts with established methods of reconstruction either in autologous or allogeneic matter. They also consider other possibilities for restoring defects with the help of regenerative medicine and tissue engineering approaches. In daily practice, surgeons face huge challenges and limitations, notably the lack of donor tissues or the absence of suitable recipient area for free tissue transfer. Therefore, prosthetics offer an alternative and can improve the quality of life for patients. The head and neck area is very important in terms of function and shape. Of course, it is very important that a face look like a normal face. Our science is dedicated to discovering more solutions to these limitations and to providing optimal functional results to our patients.

The Journal of Anaplastology provides a forum for new contributions, innovations and technical skills that aim to develop materials to replace or restore defects through prosthetic science. The journal was launched to advance the custom design of materials and rehabilitative prostheses for the head and neck and limbs. Such advancement requires on-going dialogue among all specialties. Our objective is to continually reform indications for treatment and reconstruction for all tissues and thus to improve not only the functional results of our work but also aesthetic results.

By glancing at the last issues of last year's volume, one can tell that the journal already published a broad range of articles. Included were articles on tumour surgery and reconstruction of the face, planning models for surgeons as an educational tool and yet more articles on different body parts including the genital area. Several articles shed insight on the prosthetic reconstruction of the nose and ear. With the release of the current issue, its third volume, it has become well known that the Journal of Anaplastology will draw attention because of its open-access style and invite collaboration from diverse disciplines. I encourage all scholars and students to be a part and to publish their work in this rapidly growing journal.

*Corresponding author: Ziyad Alharbi, Department of Plastic, Reconstructive and Hand Surgery - Burn Center, Medical Faculty, RWTH Aachen University, Pauwelsstr. 30, D-52074 Aachen, Germany, Tel: +49-241-80-0; E-mail: zalharbi@ukaachen.de

Received January 16, 2014; Accepted January 20, 2014; Published January 24 2014

Citation: Alharbi Z (2014) Anplastology: Moving Forward. Anaplastology 3: e112. doi: 10.4172/2161-1173.1000e112

Copyright: @ 2014 Alharbi Z. This is an open-access article distributed under the terms of the Creative Commons Attribution License, which permits unrestricted use, distribution, and reproduction in any medium, provided the original author and source are credited. 